\title{
Ustekinumab is effective in biological refractory Crohn's disease patients-regardless of approval study selection criteria
}

\author{
Sadik Saman, Martin Goetz, Judith Wendler, Nisar P. Malek, Jan Wehkamp, Thomas Klag \\ Department of Internal Medicine I, University Hospital Tübingen, Tübingen, Germany
}

Background/Aims: Ustekinumab is effective in active Crohn's disease. In a retrospective study, we assessed the clinical outcome in nonresponders to anti-tumor necrosis factor therapy, and/or conventional therapy and/or the $\alpha 4 \beta 7$-integrin inhibitor vedolizumab. As approval study populations do not always reflect the average "real world" patient cohort, we assessed weather patients who would not have qualified for approval studies show similar outcomes. Methods: Forty-one patients with mild to severe active Crohn's disease were treated with ustekinumab (intravenous $6 \mathrm{mg}$ per $\mathrm{kg} /$ body weight) followed by subcutaneous ustekinumab $(90 \mathrm{mg})$ at week 8 . Depending on the clinical response maintenance therapy was chosen every 8 or 12 weeks. Clinical response was defined by Crohn's Disease Activity Index (CDAI) decline, decline of stool frequency or clinical improvement. Inclusion criteria for approval studies were assessed. Results: The $58.5 \%(24 / 41)$ showed clinical response to ustekinumab. The 58.3\% of this group (14/24) achieved clinical remission. Clinical response correlated significantly with drop of stool frequency and improvement of CDAI score. The 39 out of 41 patients had no side effects and we observed no serious infections. About a third of our patients would not have met ustekinumab approval study criteria. However, patients who did not meet study criteria showed clinical improvement numerically in the same range compared to patients who would have qualified for approval studies. Conclusions: Ustekinumab is effective, safe and well tolerated in a highly therapy refractory patient cohort. Even though a reasonable number of patients did not meet ustekinumab approval study criteria, approval study results seem to be representative to the overall patient cohort. (Intest Res 2019;17:340-348)

Key Words: Crohn disease; Ustekinumab; Biological therapy

\section{INTRODUCTION}

Crohn's disease (CD) is a chronic IBD mediated by different factors such as genetics, environment (e.g., food and smoking) and changes of gut microbiota-host interactions, altered by defects in the innate immune system of the gut. ${ }^{1,2}$ Typically transmural lesions are observed and the whole gastrointesti-

Received February 1, 2019. Revised April 15, 2019. Accepted April 18, 2019 Correspondence to Thomas Klag, Department of Internal Medicine I, University Hospital Tübingen, Otfried-Müller-Str. 10, 72076 Tübingen, Germany. Tel: +49-7071-29-0, Fax: +49-7071-29-25272, E-mail: thomas. klag@med.uni-tuebingen.de

ORCID Thomas Klag (https://orcid.org/0000-0001-6286-1226) nal tract can be affected being characterized by periods of activity and remission. ${ }^{3,4}$

The 0.3 to 20.1 cases per 100,000 persons in North America and 0.3 to 12.7 cases per 100,000 in European countries are affected by $\mathrm{CD} .{ }^{5}$ Especially in newly industrialized countries with Western lifestyle the incidence is rising in the past decade. ${ }^{6}$ In these lines nutritional factors like high intake of polysatured fat or low levels of vitamin D might increase the risk of developing IBD. ${ }^{7.8}$ Furthermore lifestyle dysbalances like disturbed sleep, stress and low physical activity are associated with a higher risk of $\mathrm{CD},{ }^{9,10}$ and vice versa, psychological issues like anxiety and quality of life are often affected by $\mathrm{CD}{ }^{11}$

Current approved therapies for induction and maintenance 
of $\mathrm{CD}$ are corticosteroids, thiopurines, and biologicals including anti-TNF-antibodies, anti-integrin-antibodies like vedolizumab accomplished by the anti-interleukin 12 (IL-12) and IL-23 antibody ustekinumab. ${ }^{12}$ Biologicals like anti-TNF agents (e.g., infliximab and adalimumab) are safe and effective but there is a significant rate of primary and secondary nonresponse affecting about $36 \%$ to $40 \%$ of patients. ${ }^{13-15}$ Also the anti-integrin-antibody vedolizumab leads to sustained clinical remission in $27.7 \%$ of anti-TNF nonresponders at week 52 among patients who responded to vedolizumab induction at week $6 .^{16}$ Despite this significant progress in treatment options for IBD, about $50 \%$ of CD patients need to be operated within 10 years of diagnosis and nearly $25 \%$ undergo a second operation within 5 years after first surgery. ${ }^{17}$ Therefore, there is a tremendous medical need for development of further effective and safe drugs. ${ }^{18-21}$

In the past years it came apparent, that an abnormal high IL-12 and IL-23 production might be one of the core inflammatory pathways activated in $\mathrm{CD}^{22-24}$ In these lines ustekinumab (STELARA ${ }^{\circledR}$ ), a monoclonal antibody against the common p40 subunit of IL-12 and IL-23, was approved for the treatment of patients with moderate to severe active CD in 2016 (United States) and 2017 in Europe. ${ }^{25}$

The approval was based on a phase IIb study (CERTIFI) and phase III study (UNITI), showing effectiveness of ustekinum$\mathrm{ab}$ in induction and maintenance of remission in anti-TNF refractory and anti-TNF naive CD patients. However, clinical experience outside these studies is still limited. ${ }^{26,27}$ Furthermore, in daily clinical care we often treat patients with biologicals like ustekinumab who would not have qualified for the abovementioned approval studies. Those patients would not have met inclusion/exclusion criteria for various reasons. One common reason is, e.g., the CDAI range of therapy refractory patients which is often above or below the selection range of studies, despite clinical CD activity and need for therapy.

Therefore, the purpose of our retrospective analysis was to assess the clinical outcome in a selected, difficult to treat, tertiary care center patient group treated with ustekinumab, selected for therapy independent of phase II/III study inclusion criteria in a real-world setting. Finally, we evaluated potential markers of response including CRP, CDAI, and hemoglobin $\mathrm{Hb}$ values.

\section{METHODS}

We performed a retrospective analysis of patients with $\mathrm{CD}$ who have been treated with ustekinumab at the University Hospital Tübingen. The study was approved by the ethic committee of the University of Tübingen (approval No. 687/2012B01). Written informed consents were obtained. A group of 41 patients (>18 years) with mild to severe active CD (CDAI score, 93-775) who had either lost response or were intolerant to either conventional therapy (e.g., steroids, azathioprine, and methotrexate; $\mathrm{n}=32$ ), vedolizumab $(\mathrm{n}=10)$ or TNF- $\alpha$-antagonists (with or without vedolizumab therapy before; $\mathrm{n}=37$ ) were treated with ustekinumab. Concomitant therapies with stable doses of azathioprine, methotrexate or steroids were permitted. Key inclusion criteria included diagnosis of $\mathrm{CD} \geq 6$ months before screening.

Therapy algorithm was intravenous treatment $(6 \mathrm{mg} / \mathrm{kg} / \mathrm{body}$ weight) at week 0 followed by subcutaneous ustekinumab (90 $\mathrm{mg}$ ) at week 8. Depending on the clinical response patients were then either stopped or received maintenance therapy every 8 or 12 weeks (decision drawn by clinical observation, in terms of clinical response and patient well-being).

\section{Data Collection}

Baseline data were sex, age, weight, duration of disease, CRP values, CDAI, prior medication, failure of previous treatment (any immunomodulatory drug, TNF-antagonist, failure criteria, primary/secondary nonresponse) (Tables 1,2).

Date of first ustekinumab application, concomitant medications, adverse events and the reason for discontinuation (intolerance, loss of response) were documented. Before starting therapy with ustekinumab Hb-values, CRP, CDAI and clinical assessment were documented.

\section{Criteria for Clinical Response and Reason for Discontinuation of Ustekinumab}

Clinical response was defined by either CDAI decline of more than 100 points, decline of stool frequency or clinical improvement as reported by patients (well-being) and physician's global assessment. Clinical remission was defined as CDAI score of less than 150 points (for patients whose CDAI was above before therapy). Three patients were treated with ustekinumab even though they had a CDAI score $<150$ defined as remission. These patients were treated with ustekinumab because they lost response or became intolerant to their previous biological therapy ( 1 vedolizumab or 2 TNF- $\alpha$-antagonists) and were early changed in a status of clinical remission, before exerting flare up ( $1 / 3$ bridged with steroid use). In these patients, response was defined, e.g., as further clinical improvement 
Table 1. Baseline Characteristics of Patients with Remission (CDAl $<150$ ) and Mild Disease Activity (CDAl 151-220) before Application of Ustekinumab

\begin{tabular}{|c|c|}
\hline Characteristic & Value $(n=13)$ \\
\hline \multicolumn{2}{|l|}{ Sex } \\
\hline Male & $10(77)$ \\
\hline Female & $3(23)$ \\
\hline Mean age (yr) & 36.3 \\
\hline Median weight (kg) & 64.0 \\
\hline Mean duration of disease (yr) & 11.1 \\
\hline Median CRP $(\mathrm{mg} / \mathrm{dL})(\mathrm{n}=11)^{\mathrm{a}}$ & 0.8 \\
\hline \multicolumn{2}{|l|}{ CRP level at baseline ${ }^{a}$} \\
\hline$\leq 0.5 \mathrm{mg} / \mathrm{dL}$ & $4(31)$ \\
\hline$>0.5 \mathrm{mg} / \mathrm{dL}$ & $7(54)$ \\
\hline \multicolumn{2}{|l|}{ CDAl at baseline } \\
\hline$\leq 150$ & $3(23)$ \\
\hline $151-220$ & $10(77)$ \\
\hline \multicolumn{2}{|l|}{ CD drugs at baseline } \\
\hline Aminosalicylate drug & $2(15)$ \\
\hline Glucocorticoid & $5(38)$ \\
\hline \multicolumn{2}{|l|}{ Failure of previous treatment } \\
\hline Any immunomodulatory drugs & $11(85)$ \\
\hline \multicolumn{2}{|l|}{ Anti-TNFs at baseline } \\
\hline 1 & $10(77)$ \\
\hline$>1$ & $1(7)$ \\
\hline Anti-TNF+vedolizumab at baseline & $2(75)$ \\
\hline \multicolumn{2}{|l|}{ Failure criteria met } \\
\hline Primary nonresponse & $5(38)$ \\
\hline Secondary nonresponse within 8 months & 0 \\
\hline Unacceptable side effects & $1(7)$ \\
\hline Stoma & $3(23)$ \\
\hline
\end{tabular}

Values are presented as number (\%).

${ }^{a}$ Normal CRP level was defined as $\leq 0.5 \mathrm{mg} / \mathrm{mL}$.

(stool frequency and abdominal pain) or maintenance of previous remission. In all patients' criteria for discontinuation were primary nonresponse (nonresponse 8 weeks after the first application), secondary nonresponse (initial response during maintenance therapy turned to loss of response) or intolerance.

\section{Statistics}

The presented graphs were generated using GraphPad Prism version 7 (GraphPad Software Inc., La Jolla, CA, USA). Statistical significance was assessed performing the paired $t$-test.
Table 2. Baseline Characteristics of Patients with Moderate to Severe Disease Activity (CDAl > 221) before Application of Ustekinumab

\begin{tabular}{|c|c|}
\hline Characteristic & Value $(n=28)$ \\
\hline \multicolumn{2}{|l|}{ Sex } \\
\hline Male & $9(32)$ \\
\hline Female & $19(68)$ \\
\hline Mean age (yr) & 35.5 \\
\hline Median weight (kg) & 65.0 \\
\hline Mean duration of disease (yr) & 14.3 \\
\hline Median CRP $(\mathrm{mg} / \mathrm{dL})(\mathrm{n}=24)^{\mathrm{a}}$ & 1.3 \\
\hline \multicolumn{2}{|l|}{ CRP level at baseline ${ }^{a}$} \\
\hline$\leq 0.5 \mathrm{mg} / \mathrm{dL}$ & $9(32)$ \\
\hline$>0.5 \mathrm{mg} / \mathrm{dL}$ & $15(53)$ \\
\hline \multicolumn{2}{|l|}{ CDAl at baseline } \\
\hline $221-450$ & $25(89)$ \\
\hline$>450$ & $3(11)$ \\
\hline \multicolumn{2}{|l|}{ CD drugs at baseline } \\
\hline Aminosalicylate drug & $5(18)$ \\
\hline Glucocorticoid & $10(36)$ \\
\hline \multicolumn{2}{|l|}{ Failure of previous treatment } \\
\hline Any immunomodulatory drugs & $27(96)$ \\
\hline \multicolumn{2}{|l|}{ Anti-TNFs at baseline } \\
\hline 1 & $11(39)$ \\
\hline$>1$ & $9(32)$ \\
\hline Anti-TNF+vedolizumab at baseline & $8(29)$ \\
\hline Biologicals naive & $3(11)$ \\
\hline \multicolumn{2}{|l|}{ Failure criteria met } \\
\hline Primary nonresponse & $9(32)$ \\
\hline Secondary nonresponse within 8 months & $3(11)$ \\
\hline Unacceptable side effects & $1(3)$ \\
\hline Stoma & $1(3)$ \\
\hline
\end{tabular}

Values are presented as number (\%).

${ }^{a}$ Normal CRP level was defined as $\leq 0.5 \mathrm{mg} / \mathrm{mL}$.

$P$-values $\leq 0.05$ were considered to be statistically significant.

\section{RESULTS}

\section{Patient Characteristics}

In total 41 patients with mild to severe $\mathrm{CD}$ activity were treated with ustekinumab from December 2016 to July 2018. The 38 out of 41 of the patients (92.7\%) had been treated with immunomodulatory drugs before initiation of ustekinumab. The 10 out of 41 of the patients $(24.4 \%)$ received at least one antiTNF-antibody and vedolizumab before. The 28 out of 41 of the 
patients $(68.3 \%)$ had been treated with 1 anti-TNF antibody and 10 with 2 or 3 anti-TNFs (24.4\%) before start of ustekinumab (Tables 1, 2). The 15 out of 41 of the patients $(36.6 \%)$ had concomitant therapy with glucocorticoids before application of ustekinumab. Only 3 out of 41 patients (7.3\%) were biological naive (Tables 1, 2).

The 21 out of 41 of the patients (51.2\%) were female. At the time-point of ustekinumab initiation median age of the patients was 35.9 years with a mean disease duration of 13.2 years. In 35 out of 41 patients (85.4\%) CRP values were available before initiation of ustekinumab and the median serum level was 1.6 $\mathrm{mg} / \mathrm{dL}$ (normal $\leq 0.5 \mathrm{mg} / \mathrm{dL}$ ). All clinical characteristics of the patients are listed in Tables 1 and 2.

\section{Clinical Response to Ustekinumab Therapy}

The observational period of the patients was 8 months after the first application of ustekinumab. The 14 out of 41 of the pa-
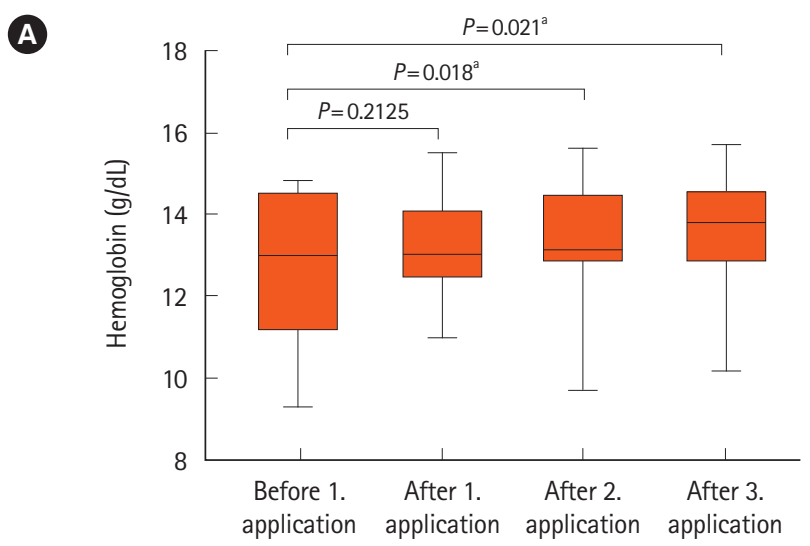

c

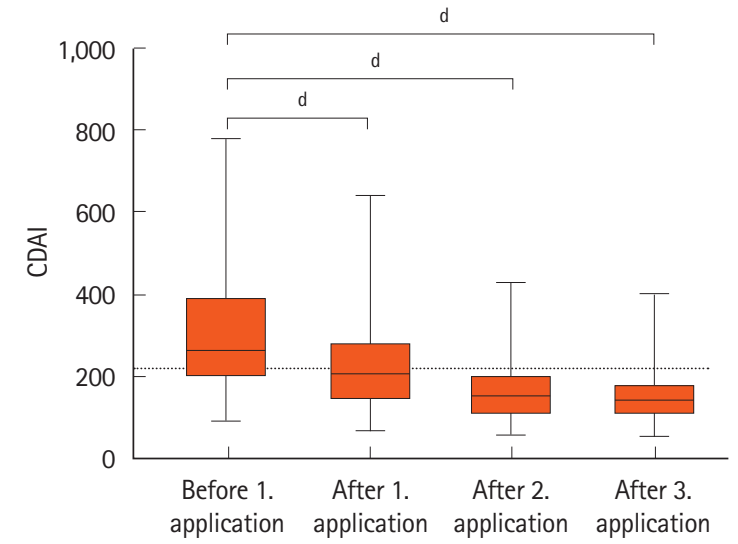

A

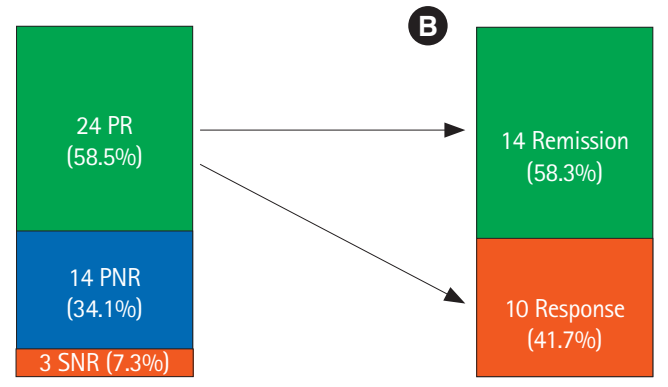

Primary response/nonresponse $(n=41)$

Characterization of primary responders $(n=24)$

Fig. 1. Overall response and nonresponse towards ustekinumab. Shown are proportion of responders and nonresponders (A) and the characterization of primary responders (B). Clinical response was defined by either CDAI decline of more than 100 points, improvement as reported by patient's well-being and physicians global assessment. Clinical remission was defined as CDAl score of less than 150 points. PR, primary response; PNR, primary nonresponse; $S N R$, secondary nonresponse (response that was not maintained).

B

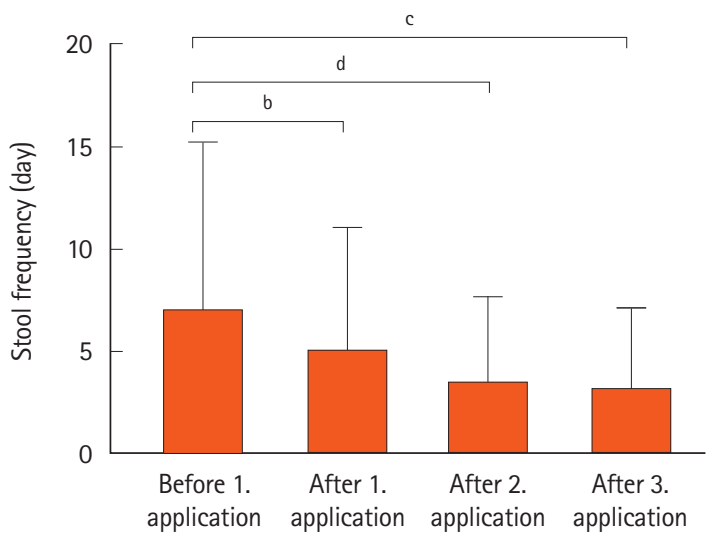

(D)

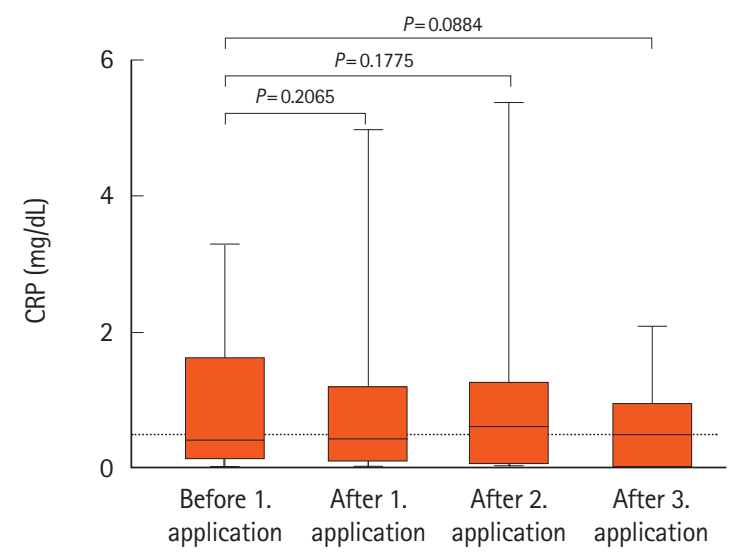

Fig. 2. Follow-up of hemoglobin, stool frequency, CDAl, and CRP levels during treatment with ustekinumab. The graphics show the development of hemoglobin (A), stool frequency (B), CDAI (C), and CRP (D) during treatment with ustekinumab in the primary responder group from week 0 (before 1. application) to week 32 (after 3. application). Dotted line in panel $\mathrm{C}$ represents the threshold of flare-ups (CDAI score $>220$ ). Dotted line in panel $D$ represents normal CRP value $<0.5 \mathrm{mg} / \mathrm{dL}$. Statistical relevance of the results was assessed performing the paired $t$-test. $P \leq 0.05$ was considered to be statistically significant. ${ }^{a} P<0.05,{ }^{b} P<0.01,{ }^{c} P<0.001,{ }^{d} P<0.0001$. 
tients (34.1\%) did not benefit from ustekinumab therapy (primary nonresponders) and in 3 cases initial response (7.3\%) turned to a secondary nonresponse with increase of diarrhea frequency or/and abdominal pain (Fig. 1A).

Vice versa patients $(24 / 41,58.5 \%)$ responded to ustekinum$\mathrm{ab}$ throughout the first 3 applications (primary responders) (Fig. 1A). Fourteen of these primary responders (58.3\%; 34.1\% of total population [14/41]) showed clinical remission (CDAI $<150)$ and 10 (41.7\%; 24.4\% of total population [10/41]) developed clinical response (CDAI decline of more than 100 points, decline of stool frequency or clinical improvement defined by patients well-being and physicians observations) (Fig. 1B).

\section{Development of Clinical Parameters in Primary Ustekinumab Responders}

A significant increase of $\mathrm{Hb}$-values could be observed after the first application of ustekinumab ( $\mathrm{n}=21 ; P=0.018)$ (Fig. 2A). In 3 responders there were no $\mathrm{Hb}$ results available before starting therapy.

Also decline of stool frequency correlated positively with response after first $(\mathrm{n}=23 ; P=0.0016)$, second $(\mathrm{n}=23 ; P=0.0001)$ and third application $(\mathrm{n}=23 ; P=0.0002)$ (Fig. 2B). A significant effect was detected in CDAI decline after first ( $\mathrm{n}=24 ; P=0.0001)$, second $(\mathrm{n}=24 ; P=0.0001)$ and third application $(\mathrm{n}=24 ; P=$ 0.0001 ), too (Fig. 2C).

After application of ustekinumab CRP levels were available in 19 responders after first, in 21 after the second and in 18 after the third application. However, there was no significant change in CRP levels after first ( $\mathrm{n}=17 ; P=0.2114)$, second $(\mathrm{n}=16 ; P=$ $0.173)$ and third application $(\mathrm{n}=13 ; P=0.092)($ Fig. 2D).

\section{Ustekinumab Outcome by CRP-level (Normal Group vs. Elevated Group)}

To further evaluate the prognostic value of baseline CRP levels, we investigated CRP-levels in 35 out of 41 of our patients, where CRP levels were available at baseline, before application of ustekinumab. Normal CRP levels are defined as $\leq 0.5$ $\mathrm{mg} / \mathrm{dL}$ in our clinical laboratory.

The 13 out of 35 had normal CRP-levels at baseline. The $69 \%$ of these patients had a primary response to ustekinumab, 23\% showed primary nonresponse and $8 \%$ presented with secondary nonresponse during therapy with ustekinumab. In the elevated group (22/35), $41 \%$ of these patients showed a primary response, whereas $50 \%$ had a primary nonresponse and $9 \%$

Table 3. Response to Ustekinumab with Respect to CRP-Level at Baseline $(n=35)$

\begin{tabular}{lcc}
\hline & $\begin{array}{c}\text { Normal group } \\
(\mathrm{CRP} \leq 0.5 \mathrm{mg} / \mathrm{dL}, \\
\mathrm{n}=13)\end{array}$ & $\begin{array}{c}\text { Elevated group } \\
(\mathrm{CRP}>0.5 \mathrm{mg} / \mathrm{dL}, \\
\mathrm{n}=\mathbf{2 2})\end{array}$ \\
\hline Primary response & $9(69)$ & $9(41)$ \\
Primary nonresponse & $3(23)$ & $11(50)$ \\
Secondary nonresponse & $1(8)$ & $2(9)$ \\
\hline
\end{tabular}

Values are presented as number (\%).
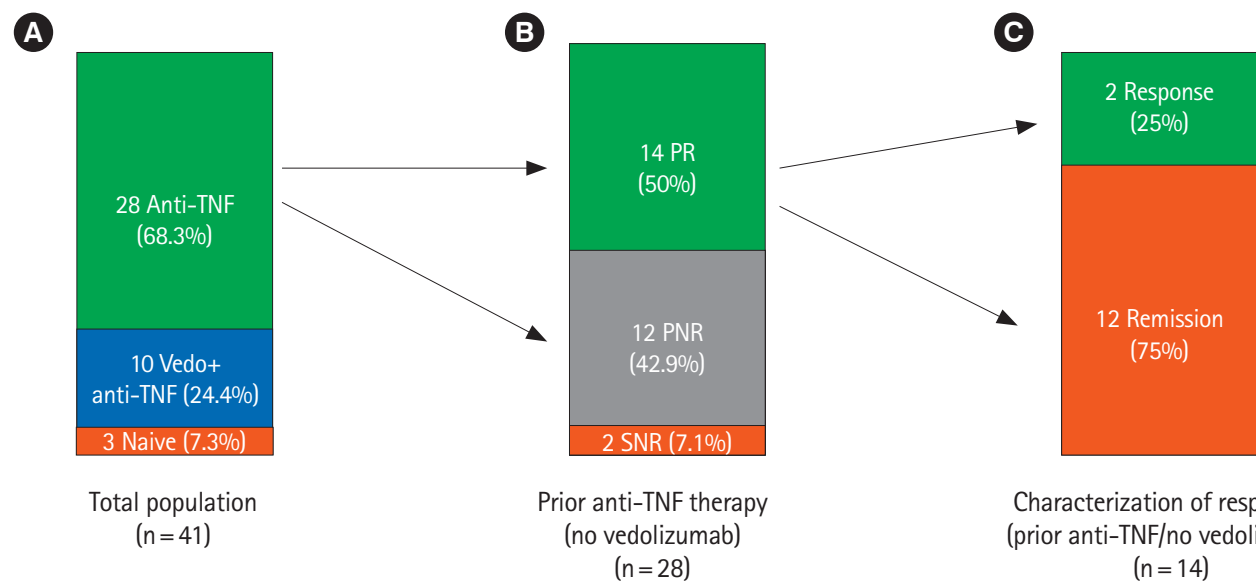

Characterization of responders (prior anti-TNF/no vedolizumab) $(n=14)$

Fig. 3. Response with respect to prior biological treatment. (A) Depicts the proportions of response with respect to prior biological treatment. Patients who had not been treated with a biological were defined as biological naive. (B) Focuses on patients with prior anti-TNF therapy. (C) Depicts response and remission of the primary responders. Clinical response was defined by either CDAl decline of more than 100 points, improvement as reported by patient's well-being and physicians global assessment. Clinical remission was defined as CDAI score of less than 150 points. PR, primary response; PNR, primary nonresponse; SNR, secondary nonresponse (response that was not maintained). 
developed a secondary nonresponse (Table 3). Therefore, patients with normal CRP-values had a higher probability of responding to ustekinumab in our patient cohort.

\section{Clinical Outcome in Anti-TNF Refractory Patients (Anti-integrin Antibody Naive)}

Of the 41 patients, $28(68.3 \%)$ had been treated with at least one anti-TNF-antibody at baseline (Fig. 3A). In this group about half of the patients $(12 / 28)$ were primary nonresponders to ustekinumab and 2 of the patients (7.1\%) developed secondary nonresponse to ustekinumab (Fig. 3B). Vice versa (14/28) were primary responders. Characterizing these primary responders, we could observe that $75 \%$ (12/14) achieved clinical remission (CDAI < 150) versus 2 patients with only a clinical response (Fig. 3C).

\section{Clinical Outcome of Anti-integrin/anti-TNF Pretreated Patients}

Ten of the patients $(10 / 41,24.4 \%)$ had been treated with vedolizumab and at least one anti-TNF antagonist before initiation of ustekinumab. Seven of these patients $(70 \%)$ showed a primary response, 2 nonresponse (20\%) and 1 secondary nonresponse (10\%) after 3 months (Fig. 4A). The 3 out of 7 of the responder $(42.9 \%)$ in this group achieved clinical remission (Fig. 4B).

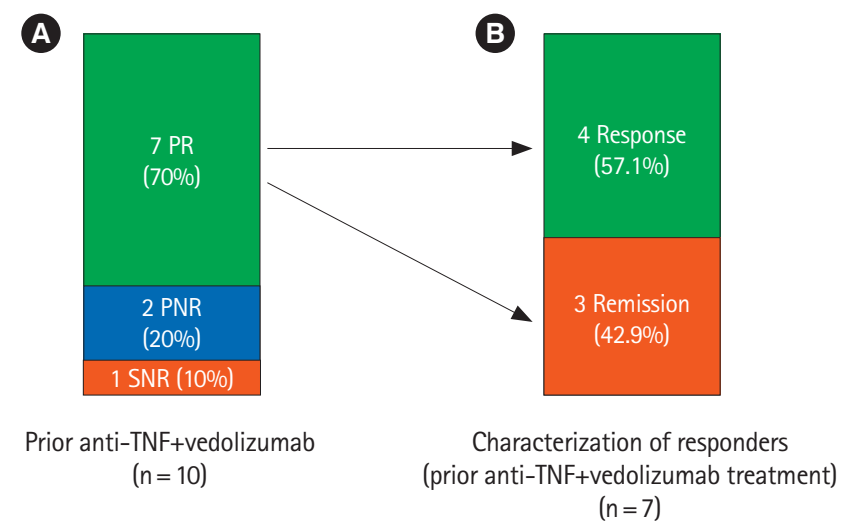

Fig. 4. Response with respect to prior therapy with vedolizumab and anti-TNF. (A) Shows response rate with respect to prior therapy with vedolizumab and anti-TNF and (B) characterizes the responders of this group. Clinical response was defined by either CDAl decline of more than 100 points, improvement as reported by patient's well-being and physicians global assessment. Clinical remission was defined as CDAl score of less than 150 points. PR, primary response; PNR, primary nonresponse; SNR, secondary nonresponse (response that was not maintained).

\section{Clinical Response to Ustekinumab Treatment According to Primary or Secondary Loss of Response to Prior Anti-TNF-Therapy}

The 17 of our patients $(17 / 37,45.9 \%)$ showed primary nonresponse to anti-TNF drugs. The 10 of these patients (10/17, $59 \%$ ) showed primary response to ustekinumab, none of these patients developed secondary loss of response to ustekinumab.

The 20 of our patient cohort $(20 / 37,54.1 \%)$ had secondary nonresponse to prior anti-TNF-therapy. The 11 of these patients $(11 / 20,55 \%)$ showed primary response to ustekinumab and 3 out of 20 (15\%) developed secondary nonresponse to ustekinumab (Table 4).

Therefore, primary failure to anti-TNF-therapy is no marker to predict primary response to ustekinumab therapy (3/41 of our cohort [7.3\%] were anti-TNF naive and in case of 1 patient there was no clear data about primary or secondary nonresponse).

\section{Side Effects to Ustekinumab}

During therapy only 2 patients $(2 / 41,4.9 \%)$ developed side effects after 3 and 5 months leading to therapy cessation. One patient was stopped because of developing arthralgia, dizziness and cephalgia and one patient because of skin blisters. The other patients (39/41) tolerated ustekinumab well. These data show an even better safety profile than the results of the approval study showing the percentages of patients with a serious adverse event being $9.9 \%$ and $12.1 \%$ with $90 \mathrm{mg}$ of ustekinumab every 8 weeks, and every 12 weeks respectively. ${ }^{27}$ Furthermore, we observed no related infections or deaths while in the approval study $2.3 \%$ in the group receiving ustekinumab every 8 weeks and 5.3\% in the group receiving ustekinumab every 12 weeks and $2.3 \%$ in the placebo group developed serious infections. ${ }^{27}$

\section{Patients Who Would Not Qualify for the Ustekinumab Approval Studies}

As outlined in the introduction we were also interested in whe-

Table 4. Primary versus Secondary Failure of anti-TNF-Relation to Type of Response to Ustekinumab Therapy $(n=37)$

\begin{tabular}{lcc}
\hline & $\begin{array}{c}\text { Primary } \\
\text { nonresponse to } \\
\text { anti-TNF }(n=17)\end{array}$ & $\begin{array}{c}\text { Secondary } \\
\text { nonresponse to } \\
\text { anti-TNF }(n=20)\end{array}$ \\
\hline Primary response & $10(59)$ & $11(55)$ \\
Primary nonresponse & $7(41)$ & $6(30)$ \\
Secondary nonresponse & 0 & $3(15)$ \\
\hline
\end{tabular}

Values are presented as number (\%). 
ther there is a difference in response to ustekinumab (in our patient cohort) between patients who would have qualified for the well-known phase II/III approval studies of ustekinum$\mathrm{ab}$ and patients who would not have qualified for these studies. This question arises from the fact, that there seems to be a gap between patient collectives of IBD biological studies and real life IBD patients in daily clinical routine. ${ }^{28}$

Sixteen patients of our cohort $(16 / 41,39 \%)$ would not have qualified for the phase II/III study inclusion criteria for different reasons-most common; CDAI > 450 ( $n=3), 150-220(n=10)$ or $<150(\mathrm{n}=3)$ but clinical active disease defined, e.g., by abdominal pain. However, 11 of these patients $(11 / 16,68.7 \%)$ were responders to ustekinumab (Fig. 5A).

\section{Patients Who Would Have Qualified for Ustekinumab Approval Studies}

Among our patient cohort (25/41,61\%) would have qualified for ustekinumab approval studies. In this group 13 (52\%) were primary responders, 9 (36\%) were primary nonresponders and $3(12 \%)$ were secondary nonresponders (Fig. 5B). One of the approval studies achieved clinical remission rates of $46.1 \%$ and $40.3 \%$, in the groups being treated with ustekinumab every 8 or 12 weeks. ${ }^{27}$

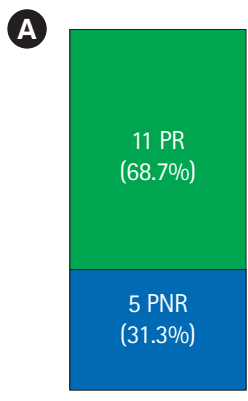

Would not qualifiy for study inclusion criteria $(n=16)$

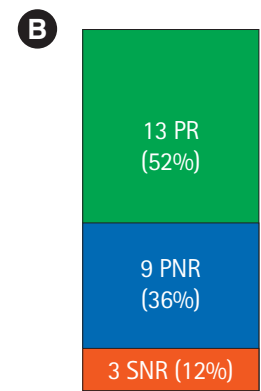

Would qualify for study inclusion criteria $(n=25)$
Fig. 5. Comparison of patients qualifying for approval studies or who would not have qualified. Shown are the proportions of patients who would not (A) and would qualify (B) for the published ustekinumab approval studies and their response rates towards ustekinumab in our patient cohort. Clinical response was defined by either CDAl decline of more than 100 points, improvement as reported by patient's well-being and physicians global assessment. Clinical remission was defined as CDAl score of less than 150 points. PR, primary response; PNR, primary nonresponse; SNR, secondary nonresponse.

\section{DISCUSSION}

In this study we retrospectively assessed the clinical outcome of CD patients' refractory to conventional therapy (i.e., corticosteroids and immunosuppressants), anti-TNFs and/or vedolizumab receiving ustekinumab over a period of 8 months ( 3 applications). Our study provides further information for the efficacy and safety of ustekinumab in a real life, difficult to treat CD patient cohort. Overall, $92.7 \%$ of our patients failed at least one anti-TNF and $24.4 \%$ failed anti-TNF and vedolizumab before switch to ustekinumab. In this cohort $58.5 \%$ of the patients had a primary clinical response to ustekinumab therapy.

Clinical response was characterized by decrease of stool frequency, normalization of stool consistency, increased wellbeing with, e.g., less episodes of abdominal pain or improved fatigue and physicians evaluation. With this overall response rate our real life data (in terms of clinical improvement) are widely in line with the known approval study data of ustekinumab showing sustained remission rates of about $50 \%$ on doses of ustekinumab every 8 or 12 weeks. ${ }^{29}$ The first real-life study about the efficacy of ustekinumab in a cohort of 38 severe antiTNF resistant CD patients with a median follow-up of 7.9 months was performed by Kopylov et al., ${ }^{30}$ showing initial clinical response in $73.7 \%$ of patients, even higher than those in our study population. One of the reasons for the difference might be the fact that our cohort consisted of extraordinarily biological resistant patients, for example ten of our patients were also refractory to vedolizumab. Kopylov et al. ${ }^{30}$ did not treat the patients with vedolizumab before. A clinical response to ustekinumab of approximately $40 \%$ in real life practice was seen in 2 other studies in a cohort of 116 and 45 with a median followup of 10 and 12 months. ${ }^{29,31,32}$

In our study there was no correlation between disease activity and the CRP-level after first, second and third application of ustekinumab. However, there are divergent data in the literature regarding CRP and its correlation to disease activity in CD. Some authors see it useful in the assessment and management of $\mathrm{CD}^{33,34}$ others do not regard it as a reliable tool for monitoring $\mathrm{CD}$ activity.

Reasons for absence of CRP increase in CD patients might be previous application of antibiotics such as ciprofloxacin or metronidazole. ${ }^{35}$ But also individual genetic factors may influence the CRP response and production. One aspect would be specific polymorphisms of the gene encoding CRP on the long arm of chromosome1 (1q23-24) leading to lower baseline of CRP production. ${ }^{36}$ 
Only 2 of the patients (4.8\%) in our cohort developed side effects to ustekinumab such as dizziness, skin blisters and arthralgia. No Infections were registered, underlining the favorable safety profile of ustekinumab in a real-life setting.

One of the main goals of our retrospective observation was to analyze the usefulness of common approval study selection criteria for biologicals in $\mathrm{CD}$ in real life patients. In clinical routine there is a diverse mixture of every kind of patients with different comorbidities and medical prehistory. However, in phase II/III studies of ustekinumab for example only patients with a CDAI-score between 220 and 450 were enrolled. In this case for example patients being treated with ustekinumab because of developing side effects towards anti-TNFs but having a clinical activity measured below CDAI $<220$ would not have been accepted in the studies. ${ }^{26,27}$ Nevertheless, in clinical routine we often encounter this kind of patients and it is questionable if approval study selection is applicable to the average patients we treat in clinical routine. In our opinion our data suggest that approval study selection criteria generate clinical data which are transferable to the average CD patient regardless of fitting to study criteria. This conclusion is based on the fact that the clinical response rates in patients who would have qualified for approval studies (in our cohort) is not higher (even below) as they are in the patients who would not have qualified (Fig. 5). Therefore, this is a first advice that the criticism on approval study design in $\mathrm{IBD}^{28}$ might not account for all biologicals.

Despite the small patient cohort and the follow-up of 8 months we believe that our study assessed valid and representative information for real-life use of ustekinumab. To sum up ustekinumab is a safe and effective drug for the treatment of patients refractory to conventional therapy, anti-TNFs and anti-integrins in $\mathrm{CD}$, regardless of fitting to study selection criteria.

\section{FINANCIAL SUPPORT}

This work was supported by the Deutsche Forschungsgemeinschaft, Germany (Heisenberg Program).

\section{CONFLICT OF INTEREST}

J.W. received speakers honoray and/or consultant fees from Takeda, AbbVie, MSD, Ferring, Roche, Novartis, Janssen. T.K. received speakers honoray and/or consultant fees from Takeda, AbbVie, MSD, Novartis, Janssen. M.G. received speakers honoray and/or consultant fees from Takeda, AbbVie, MSD,
Novartis, Janssen. Except for that, no potential conflict of interest relevant to this article was reported.

\section{AUTHOR CONTRIBUTION}

Conceptualization: Saman S, Klag T, Wehkamp J. Methodology: Saman S, Klag T, Wehkamp J. Formal analysis: Saman S, Klag T, Wehkamp J, Wendler J, Goetz M. Funding acquisition: Wehkamp J, Malek NP. Project administration: Saman S, Klag T. Visualization: Saman S, Klag T, Wehkamp J, Wendler J, Malek NP. Writing - original draft: Saman S, Klag T, Wehkamp J. Writing - review and editing: all. Approval of final manuscript: all authors.

\section{REFERENCES}

1. Ananthakrishnan AN. Epidemiology and risk factors for IBD. Nat Rev Gastroenterol Hepatol 2015;12:205-217.

2. Wehkamp J, Stange EF. Paneth's disease. J Crohns Colitis 2010; 4:523-531.

3. Ballester Ferré MP, Boscá-Watts MM, Mínguez Pérez M. Crohn's disease. Med Clin (Barc) 2018;151:26-33.

4. Klag T, Stange EF, Wehkamp J. Defective antibacterial barrier in inflammatory bowel disease. Dig Dis 2013;31:310-316.

5. Hibi T, Imai Y, Murata Y, Matsushima N, Zheng R, Gasink C. Efficacy and safety of ustekinumab in Japanese patients with moderately to severely active Crohn's disease: a subpopulation analysis of phase 3 induction and maintenance studies. Intest Res 2017;15:475-486.

6. Ng SC, Shi HY, Hamidi N, et al. Worldwide incidence and prevalence of inflammatory bowel disease in the 21st century: a systematic review of population-based studies. Lancet 2018; 390:2769-2778.

7. Hart AR, Luben R, Olsen A, et al. Diet in the aetiology of ulcerative colitis: a European prospective cohort study. Digestion 2008;77:57-64.

8. Ananthakrishnan AN, Cagan A, Gainer VS, et al. Normalization of plasma 25-hydroxy vitamin $\mathrm{D}$ is associated with reduced risk of surgery in Crohn's disease. Inflamm Bowel Dis 2013;19:1921-1927.

9. Sonnenberg A. Occupational distribution of inflammatory bowel disease among German employees. Gut 1990;31:10371040.

10. Ananthakrishnan AN, Khalili H, Konijeti GG, et al. Sleep duration affects risk for ulcerative colitis: a prospective cohort study. Clin Gastroenterol Hepatol 2014;12:1879-1886. 
11. Klag T, Mazurak N, Fantasia L, et al. High demand for psychotherapy in patients with inflammatory bowel disease. Inflamm Bowel Dis 2017;23:1796-1802.

12. Amiot A, Peyrin-Biroulet L. Current, new and future biological agents on the horizon for the treatment of inflammatory bowel diseases. Therap Adv Gastroenterol 2015;8:66-82.

13. Hanauer SB, Feagan BG, Lichtenstein GR, et al. Maintenance infliximab for Crohn's disease: the ACCENT I randomised trial. Lancet 2002;359:1541-1549.

14. Rutgeerts P, Feagan BG, Lichtenstein GR, et al. Comparison of scheduled and episodic treatment strategies of infliximab in Crohn's disease. Gastroenterology 2004;126:402-413.

15. Sandborn WJ, Rutgeerts P, Enns R, et al. Adalimumab induction therapy for Crohn disease previously treated with infliximab: a randomized trial. Ann Intern Med 2007;146:829-838.

16. Sands BE, Sandborn WJ, Van Assche G, et al. Vedolizumab as induction and maintenance therapy for Crohn's disease in patients naïve to or who have failed tumor necrosis factor antagonist therapy. Inflamm Bowel Dis 2017;23:97-106.

17. Frolkis AD, Lipton DS, Fiest KM, et al. Cumulative incidence of second intestinal resection in Crohn's disease: a systematic review and meta-analysis of population-based studies. Am J Gastroenterol 2014;109:1739-1748.

18. Gisbert JP, Marín AC, McNicholl AG, Chaparro M. Systematic review with meta-analysis: the efficacy of a second anti-TNF in patients with inflammatory bowel disease whose previous anti-TNF treatment has failed. Aliment Pharmacol Ther 2015; 41:613-623.

19. Feagan BG, Schwartz D, Danese S, et al. Efficacy of vedolizumab in fistulising Crohn's disease: exploratory analyses of data from GEMINI 2. J Crohns Colitis 2018;12:621-626.

20. Ford AC, Bernstein CN, Khan KJ, et al. Glucocorticosteroid therapy in inflammatory bowel disease: systematic review and meta-analysis. Am J Gastroenterol 2011;106:590-599.

21. Estevinho MM, Afonso J, Rosa I, et al. A systematic review and meta-analysis of 6-thioguanine nucleotide levels and clinical remission in inflammatory bowel disease. J Crohns Colitis 2017;11:1381-1392.

22. Monteleone G, Biancone L, Marasco R, et al. Interleukin 12 is expressed and actively released by Crohn's disease intestinal lamina propria mononuclear cells. Gastroenterology 1997; 112:1169-1178.

23. Simon EG, Ghosh S, Iacucci M, Moran GW. Ustekinumab for the treatment of Crohn's disease: can it find its niche? Therap Adv Gastroenterol 2016;9:26-36.
24. Berrebi D, Besnard M, Fromont-Hankard G, et al. Interleukin-12 expression is focally enhanced in the gastric mucosa of pediatric patients with Crohn's disease. Am J Pathol 1998;152:667672.

25. Barré A, Colombel JF, Ungaro R. Review article: predictors of response to vedolizumab and ustekinumab in inflammatory bowel disease. Aliment Pharmacol Ther 2018;47:896-905.

26. Sandborn WJ, Gasink C, Gao LL, et al. Ustekinumab induction and maintenance therapy in refractory Crohn's disease. N Engl J Med 2012;367:1519-1528.

27. Feagan BG, Sandborn WJ, Gasink C, et al. Ustekinumab as induction and maintenance therapy for Crohn's disease. N Engl J Med 2016;375:1946-1960.

28. Ha C, Ullman TA, Siegel CA, Kornbluth A. Patients enrolled in randomized controlled trials do not represent the inflammatory bowel disease patient population. Clin Gastroenterol Hepatol 2012;10:1002-1007.

29. Koelewijn CL, Schwartz MP, Samsom M, Oldenburg B. C-reactive protein levels during a relapse of Crohn's disease are associated with the clinical course of the disease. World J Gastroenterol 2008;14:85-89.

30. Kopylov U, Afif W, Cohen A, et al. Subcutaneous ustekinumab for the treatment of anti-TNF resistant Crohn's disease: the McGill experience. J Crohns Colitis 2014;8:1516-1522.

31. Wils P, Bouhnik Y, Michetti P, et al. Long-term efficacy and safety of ustekinumab in 122 refractory Crohn's disease patients: a multicentre experience. Aliment Pharmacol Ther 2018;47:588-595.

32. Harris KA, Horst S, Gadani A, et al. Patients with refractory crohn's disease successfully treated with ustekinumab. Inflamm Bowel Dis 2016;22:397-401.

33. Khorrami S, Ginard D, Marín-Jiménez I, et al. Ustekinumab for the treatment of refractory Crohn's disease: the Spanish experience in a large multicentre open-label cohort. Inflamm Bowel Dis 2016;22:1662-1669.

34. Fagan EA, Dyck RF, Maton PN, et al. Serum levels of C-reactive protein in Crohn's disease and ulcerative colitis. Eur J Clin Invest 1982;12:351-359.

35. Filik L, Dagli U, Ulker A. C-reactive protein and monitoring the activity of Crohn's disease. Adv Ther 2006;23:655-662.

36. Chamouard P, Richert Z, Meyer N, Rahmi G, Baumann R. Diagnostic value of $\mathrm{C}$-reactive protein for predicting activity level of Crohn's disease. Clin Gastroenterol Hepatol 2006;4:882887. 